\title{
NOTAS SOBRE A TÉCNICA E O ENSINO DE FILOSOFIA EM MARTIN HEIDEGGER
}

\author{
Leonardo Henrique Morais Martins ${ }^{1}$ \\ Gustavo Silvano Batista ${ }^{2}$
}

\begin{abstract}
Resumo:
O presente artigo discute o texto de Heidegger 'A questão técnica' e seus desdobramentos na prática de ensino de filosofia na educação básica. Tendo em vista a reflexão heideggeriana sobre a essência da técnica, especialmente no que diz respeito a configuração da nossa época histórica, busca-se analisar o questionamento filosófico essencial, nos termos de um pensamento originário, que ressalte a essência da técnica como um elemento que não é puramente técnico. Tal reflexão indica um traço importante para a educação filosófica na escola, à medida que pensa o domínio técnico na educação e a necessidade de questionar tal domínio através de um pensamento que retoma a pergunta pela essência da técnica no ambiente escolar. Assim, o percurso, pensado como notas, acompanha a argumentação de Heidegger, repercutindo a discussão na escola, especialmente na formação filosófica básica, tendo em vista todo o ambiente técnico que vivemos, seja pela influência das ciências positivas, seja pela presença do aparato tecnológico na escola.
\end{abstract}

Palavras-chave: Técnica. Heidegger. Ensino. Escola.

\section{NOTES ON TECHNICS AND TEACHING OF PHILOSOPHY IN MARTIN HEIDEGGER}

\begin{abstract}
:
This article discusses Heidegger's text 'The question concerning technology' and its consequences in the practice of teaching philosophy in basic education. In view of Heidegger's reflection on the essence of the technology, especially about the configuration of our historical time, we seek to analyze the essential philosophical questioning, in terms of an original thought, which highlights the essence of the technology as an element that is not purely technical. Such reflection indicates an important trace for philosophical education at school, as one thinks about the technical domain in education and the need to question this domain through a thought that takes up the question of the essence of technology in the school environment. Thus, the way, thought as notes, follows Heidegger's argument, reflecting the discussion at school, especially in the basic philosophical training, considering the entire technical environment that we live, due to the influence of positive sciences and/or the presence of the technological apparatus in school.
\end{abstract}

Keywords: Technology. Heidegger. Teaching. School.

\section{Introdução}

Em 1953, Heidegger apresenta o texto "A Questão Técnica”, contemplando especialmente os impactos do desenvolvimento tecnológico na vida da Europa após segunda guerra. Em linhas gerais, o autor reflete sobre o modo como o domínio cada vez maior da

1 Mestre em Filosofia pela Universidade Federal do Tocantins. Professor de filosofia no Ensino Básico no Estado do Tocantins. E-mail: leonardoloughan@gmail.com.

2 Doutor em Filosofia pela Pontifícia Universidade Católica do Rio de Janeiro. Professor do Departamento de Filosofia da Universidade Federal do Piauí. Professor permanente no PPGFIL-UFPI e professor colaborador no PROF-FILO/UFT. E-mail: gustavosilvano@ufpi.edu.br. 
técnica modificou de forma radical o modo como o homem se relaciona com o mundo e com os outros, transformando as relações de tal modo que não poderíamos pensá-las sem o mesmo traço técnico. Entre as mais importantes relações a serem tratadas, diante da influência da técnica, está a educação, pois se trata de uma esfera também transformada e fundamentalmente marcada pelos desenvolvimentos técnicos. Deste modo, o presente artigo pretende analisar as implicações da técnica na educação, a partir de Heidegger, pensando especialmente seus desdobramentos na educação básica. Compreendemos que a reflexão sobre essa questão é decisiva para perceber o sentido e os desafios da educação contemporânea, visualizando a própria educação como um problema a ser repensado.

Partindo da reflexão de Heidegger, é importante ressaltar que as suas considerações sobre a técnica têm um cunho ontológico. Ou seja, busca-se tratar da questão de modo básico, crítico aos desdobramentos da metafísica ocidental. Neste horizonte, o tema da técnica aparece como um elemento a ser fundamentalmente analisado, tendo em vista seu modo de ser. Deste modo, o tratamento da técnica não poderia se dar de modo ôntico, mas ontológico. Trata-se de um problema filosófico que coloca em questão a própria atividade da filosofia ocidental à medida que, para o autor, a técnica não é um problema técnico, mas, antes de tudo, filosófico. Por isso, torna-se necessário seguirmos um caminho no qual se busca um caminho que nos leve à essência da técnica.

Há um entendimento fortemente difundido segundo o qual a técnica teria uma natureza neutra, sendo o homem o único responsável pela sua utilização, compreendendo a técnica como um meio para algum fim. Essa neutralidade da técnica aparece como um incentivo para um entendimento técnico da natureza, tendo em vista seu próprio bem como um fim a ser alcançado por esse meio. Deste modo, todas as coisas passam a ser consideradas na perspectiva técnica. O que também inclui a educação e, mais especificamente, o ensino de filosofia na escola.

\section{A questão da essência da técnica}

Heidegger, em seu artigo sobre a técnica, surgido como uma versão preliminar em 1949 no Clube de Bremen e depois, em sua segunda versão, como uma palestra para a Academia Bávara de Belas Artes, concentra-se a pensar a essência da técnica enquanto um traço da história da metafísica ocidental. Ou seja, coloca-se novamente em um caminho de

\begin{tabular}{|c|c|c|c|c|}
\hline Qovista Dialectus & Ano 9 & n. 17 & Maio - Agosto 2020 & p.152-165 \\
\hline
\end{tabular}


investigação da questão básica desde sempre perseguida, a questão do ser, sem ignorar os impactos da guerra e as consequentes transformações da cultura ocidental. Por isso, a pergunta ontológica sobre a técnica - ou seja - sua essência, indica ainda uma ligação com a questão do ser, buscando compreender a presença da técnica como um elemento crucial para a adequada pergunta sobre a questão tratada.

A técnica não é igual à essência da técnica. Quando procuramos a essência de uma
árvore, temos de nos aperceber de que aquilo que rege toda árvore, como árvore, não
é, em si mesmo, uma árvore que pudesse encontrar entre as árvores. Assim a
essência da técnica não é, de forma alguma, nada de técnico. Por isso nunca faremos
a experiência de nosso relacionamento com a essência da técnica enquanto
concebermos e lidarmos apenas como que é técnico, enquanto a ele nos moldarmos
ou dele nos afastarmos. Haveremos sempre de ficar presos, sem liberdade, à técnica
tanto na sua afirmação como na sua negação apaixonada. A maneira mais teimosa,
porém, de nos entregarmos à técnica é considerá-la neutra, pois essa concepção, que
hoje goza de um favor especial, nos torna inteiramente cego para a essência da
técnica (HEIDEGGER, 2008, p. 11).

Para o filósofo da floresta negra, a essência de uma coisa é aquilo que efetivamente ela é; e, dessa forma, questionar a técnica é, antes de tudo, perguntar o que ela é, tendo em vista a natureza ontológica - e não técnica - da pergunta. Geralmente são dadas duas repostas a essa pergunta, consideradas definições predominantemente difundidas: uma primeira resposta diz que a técnica é meio para um fim; uma segunda definição afirma que a técnica é uma atividade especialmente humana. Contudo, ambas as respostas procuram estabelecer a técnica como uma aliada à natureza humana e seu desenvolvimento civilizacional. Nesse sentido Heidegger prossegue:

[...] pertence à técnica a produção e o uso de ferramentas, aparelhos e máquinas, assim como a ela pertencem estes produtos e utensílios em si mesmos e as necessidades a que eles servem. O conjunto de tudo isto é a técnica. A própria técnica é também um instrumento, em latim instrumentum. A concepção corrente da técnica de ser ela meio e uma atividade humana pode se chamar, portanto, a determinação instrumental a antropológica da técnica (HEIDEGGER, 2008, p. 12).

Essa determinação instrumental da técnica é que define, de acordo com Heidegger, a técnica moderna, ou seja, como um meio para um fim. Por isso, o domínio da técnica passa a ser a sua pretensão final e urgente. Porém, tal compreensão moderna traz um perigo: a técnica tem em sua constituição a possibilidade de escapar do controle do homem. Embora a determinação instrumental da técnica esteja correta, ainda não consegue desvelar sua essência de modo satisfatório. Por isso, para chegarmos à sua essência, ou pelo menos nos aproximarmos dela, devemos nos perguntar o que é o instrumental nele mesmo. A que

\begin{tabular}{|c|c|c|c|c|}
\hline Revista Dialectus & Ano 9 & n. 17 & Maio - Agosto 2020 & p.152-165 \\
\hline
\end{tabular}


pertence meio e fim? Ou seja, devemos ultrapassar o sentido instrumental e antropológico, abrindo caminho para uma abordagem ontológica da técnica.

Heidegger recorda-se de Aristóteles e seus ensinamentos metafísicos acerca das quatro causas: material, formal, final e eficiente. Desde então a instrumentalidade da técnica tem sido reduzida a essas quatro causas. Mas o autor insiste em nos indagar sobre a doutrina das causas aristotélicas: por que existem precisamente essas quatro causas? O que significa uma causa em seu sentido próprio?

Enquanto tais perguntas não forem desveladas de forma criteriosa, a causalidade, a instrumentalidade e a determinação da técnica permanecerão veladas. Para a reflexão heideggeriana, acostumamo-nos a conceber uma causa como algo eficiente, que alcança um resultado ou um efeito. Contudo, para Heidegger, a finalidade não é da ordem da causalidade.

\footnotetext{
A finalidade não pertence à causalidade, causa, casus, provém do verbo cadere, cair. Diz aquilo que com que algo caia desta ou daquela maneira num resultado. A doutrina das quatro causas remonta a Aristóteles. No entanto, para o pensamento grego e seu âmbito, tudo que a posteridade procurou entre os gregos com concepção e com o título de "causalidade" nada tem a ver com eficiência e eficácia de um fazer (HEIDEGGER, 2008, p. 14).
}

Para Heidegger, a doutrina aristotélica não explora suficientemente a causa eficiente e nem lhe conceitualiza de forma originária. Embora sejam diferentes, as quatro causas se tornam uma unidade e uma coerência na determinação da essência de alguma coisa. "Construir uma casa ou criar qualquer outro objeto técnico, não é um ato por meio qual meramente se produz uma coisa, e sim, um modo de fazer viger os quatro modos da vigência, as quatro causas aristotélicas" (WEBER, 2014, p. 96).

Seguindo a indagação de Heidegger, podemos também perguntar: "o que os une antecipadamente? Em que se joga o jogo de articulação dos quatro modos de responder o dever? De onde provém a unidade das quatro causas? Pensando de maneira grega, o que significa responder e dever?” (HEIDEGGER, 2008, p. 15). Podemos perceber, junto a Heidegger, que em nossa época há uma tendência em entender a responsabilidade em sentido moral. Contudo, tal tendência dificulta a compreensão do sentindo grego originário da causalidade, esquecendo uma percepção genuína da instrumentalidade que repousa na causalidade.

Assim, é necessário esclarecer o sentido genuíno do que é dever e responder. Para Heidegger, os quatro modos de responder e dever conduzem ao aparecer e o viger. Nesse

\begin{tabular}{|l|l|l|l|l|}
\hline Qevista Dialectus & Ano 9 & n. 17 & Maio - Agosto 2020 & p.152-165 \\
\hline
\end{tabular}


sentido, o deixar responder e dever podem ser compreendidos como vigência, presente na experiência mais ampla e originária da essência grega da causalidade. $\mathrm{O}$ significado restrito da expressão 'deixar-viger' oferece uma espécie de causa secundária da causalidade.

No Banquete, Platão nos diz que todo deixar-viger procede do não vigente para a vigência e produção. Da mesma forma, cabe agora pensarmos de modo radical a produção e o produzir, tendo como caminho a amplitude do pensamento grego originário.

\begin{abstract}
Assim os modos de deixar-viger, as quatro causas, jogam no âmbito da pro-dução e do pro-duzir. É por força desse último que advém a seu aparecimento próprio, tanto o que cresce na natureza como também o que se confecciona no artesanato e se cria na arte. Mas como é que se dá e acontece a pro-dução e o pro-duzir, seja na natureza, seja no artesanato, seja na arte? O deixar-viger concerne à vigência daquilo que, na pro-dução e no pro-duzir, chega a aparecer e apresentar-se. A pro-dução conduz do encobrimento para o desencobrimento. Só se dá no sentido próprio de uma pro-dução, enquanto e na medida em que alguma coisa encoberta chega ao desencobrir-se. Este chegar repousa e oscila no processo que chamamos de desencobrimento (HEIDEGGER, 2008, p. 16).
\end{abstract}

Nesta questão, os gregos possuíam a palavra alétheia ${ }^{3}$, traduzida pelos romanos por veritas ${ }^{4}$. Para Heidegger, a essência da técnica está intimamente ligada ao sentido do desencobrimento, fundamentando-se assim toda produção. O questionamento do traço fundamental da técnica, comumente conceituada como meio para certos fins, tem sua essência na ideia de desencobrimento.

\begin{abstract}
A técnica não é, portanto, um simples meio. A técnica é uma forma de desencobrimento. Levando isso em conta, abre-se diante de nós todo âmbito para a essência da técnica. Trata-se do âmbito do desencobrimento, isto é, da verdade. Esta perspectiva nos traz estranheza. E o deve fazer, e o fazer no maior tempo possível e de maneira tão impressionante que, finalmente levemos a sério uma simples pergunta, a pergunta do que nos diz a palavra "Técnica". É uma palavra proveniente do grego (HEIDEGGER, 2008, p. 17).
\end{abstract}

A compreensão da palavra grega nos conduz ao mesmo questionamento da questão essencial acerca do que é, na verdade, a instrumentalidade do instrumento. Dessa forma, a técnica é um desencobrimento onde uma verdade acontece, aparece. Mas, o que é a técnica moderna? Diferencia-se do contexto grego, pois se apoia em uma concepção moderna de ciência da natureza. Para Heidegger, também é desencobrimento. Contudo, o

3 Em grego clássico, A $A \eta \dot{\theta} \theta \varepsilon 1 \alpha$; sendo transcrita para Alétheia, na tradução para o português significa verdade e que também é associada à palavra romana em latim Veritas.

4 Palavra de origem romana do latim que possui o significado de verdade e que também é ligada a palavra grega Alétheia.

\begin{tabular}{|c|c|c|c|}
\hline Qevista Dialectus & Ano 9 & n. 17 & Maio - Agosto 2020 \\
\hline
\end{tabular}


desencobrimento que rege a técnica moderna é um tipo de exploração que impõe à natureza uma condição de reserva. Por isso, seu desencobrimento tem como característica a exploração.

\begin{abstract}
O desencobrimento que domina a técnica moderna possui, como característica, o pôr, no sentido de explorar. Esta exploração se dá e acontece num múltiplo movimento: a energia escondida na natureza é extraída, o extraído vê-se transformado, o transformado, estocado, o estocado, distribuído, reprocessado. Extrair, transformar, estocar, distribuir, reprocessar é todos modos de desencobrimento. Todavia, este descobrimento não se dá simplesmente. Tampouco, perde-se no indeterminado. Pelo controle, o desencobrimento abre para si mesmo suas próprias pistas, entrelaçadas numa trança múltipla diversa. Por toda parte, assegura-se o controle. Pois controle a segurança constituem até as marcas fundamentais do desencobrimento explorador (HEIDEGGER, 2008 p. 20).
\end{abstract}

A exploração, como característica da técnica moderna, carrega consigo palavras como "pôr", "dispor", “disponibilidade”, “dispositivo" etc. Todas essas palavras se fundam no caráter representativo e metafísico da linguagem humana. Por isso, o homem, do ponto de vista metafísico, pode representar, elaborar e realizar qualquer coisa. Contudo, para Heidegger, o homem não controla o desencobrimento do real que se mostra e retrai. Para ele, não foi Platão que fez com que o real se mostrasse à luz das ideias, mas apenas respondeu ao apelo que lhe atingiu.

Se o desencobrimento não for um simples feito do homem, onde é e como é que ele se dá e acontece? Não carece procurar muito longe. Basta perceber, sem preconceitos, o apelo que já sempre reivindica o homem, de maneira tão decisiva, que, somente nesse apelo, ele pode vir a ser homem. Sempre que homem abre os olhos e ouvidos e desprende o coração, sempre que se entrega a pensar sentidos e a empenhar-se por propósitos, sempre que se solta em figuras e obras ou se esmera em pedidos e agradecimentos, ele se vê inserido no que já se re-velou. O desencobrimento já se deu, em sua propriedade, todas as vezes que o homem se sente chamado ao acontecer em modos próprios de desencobrimentos (HEIDEGGER, 2008, p. 22).

Quando o homem, em suas pesquisas e investigações, trata tecnicamente a natureza, considera-a como mais um elemento representativo, comprometido pelo desencobrimento da técnica. A forma do desencobrimento própria da técnica moderna, aquela que desafia a exploração da natureza tomando-a como objeto de pesquisa, encontra na técnica seu próprio fim, à medida que torna possível o desaparecimento do próprio objeto. Entretanto, a técnica moderna não se reduz a um mero fazer do homem, por isso é necessário encarar o desafio que põe o homem a disponibilidade da natureza.

\begin{tabular}{|l|l|l|l|l|}
\hline Qevista Dialectus & Ano 9 & n. 17 & Maio - Agosto 2020 & p.152-165 \\
\hline
\end{tabular}


Permanece verdade: o homem da idade da técnica vê-se desafiando, de forma especialmente incisiva, a comprometer-se com o desencobrimento. Em primeiro lugar, ele lida com a natureza, enquanto o principal reservatório das reservas de energia. Em consequência, o comportamento do dis-positivo do homem mostra-se, inicialmente, no aparecimento das ciências modernas da natureza. Seu modo de representação encara a natureza, como um sistema operativo e calculável de forças. A física moderna não é experimental por usar, nas investigações da natureza, aparelhos e ferramentas. Ao contrário: por que, já na condição de pura teoria, a física leva a natureza a ex-por-se, como um sistema de forças, que se pode operar previamente, é que se dis-põe do experimento para testar, se a natureza confirma tal condição e modo em que o faz (HEIDEGGER, 2008, p. 24).

Heidegger também afirma que não há nenhuma dúvida que as ciências matemáticas surgiram antes da técnica moderna. A técnica moderna só começou sua marcha quando teve como apoio o desenvolvimento das ciências da natureza. Porém, a física moderna e sua teoria da natureza não preparou o caminho para técnica, muito menos para a pergunta pela essência da técnica moderna. Por essa razão, a essência da técnica moderna, segundo Heidegger, esta se encobre nas próprias atividades técnicas, mesmo com o surgimento de grandes aparatos técnicos, como as usinas.

Tudo que é essencial, não apenas a essência da técnica modera, se mantém, por toda parte, o maior tempo possível, encoberto. Todavia, a sua regência antecede tudo, sendo o primordial. Os pensadores gregos já sabiam, ao dizer: o primeiro, o vigor de sua regência, a nos homens só se manifesta posteriormente. O originário só se mostra ao homem por último. Por isso, um esforço de pensamento, que visa a pensar mais originariamente o que se pensou na origem, não é caturrice, sem sentido, de renovar o passado, mas a prontidão serena de espantar-se com o porvir do princípio (HEIDEGGER, 2008, p. 25).

Historicamente, o início das ciências modernas da natureza localiza-se no século

XVII; a visão matematizada do mundo moderno permitiu, entre outras razões, o desenvolvimento da técnica moderna, até o que vemos hoje como o domínio técnico das máquinas. O que permite a Heidegger compreender a essência da técnica como um elemento anterior à efetividade da mesma.

A técnica moderna precisa utilizar as ciências exatas da natureza porque sua essência repousa na com-posição. Assim nasce a aparência enganosa de que a técnica moderna se reduz à aplicação das ciências naturais. Esta aparência apenas se deixa manter enquanto não se questionar, de modo suficiente, nem proveniência da ciência moderna e nem essência da técnica moderna (HEIDEGGER, 2008, p. 25).

\begin{tabular}{|l|l|l|l|l|}
\hline Qevista Oialectus & Ano 9 & n. 17 & Maio - Agosto 2020 & p.152-165 \\
\hline
\end{tabular}


Heidegger questiona as concepções da técnica moderna para ressaltar principalmente a relação do homem, em seu modo de ser mais básico, com sua essência. A essência da técnica moderna se mostra, portanto, em sua composição. Mas o que é essa composição? Para Heidegger, não é nada de técnico nem nada mecânico. Ela é o modo em que a natureza se desencobre como disponibilidade. Assim, a composição que provoca a exploração encobre a produção e também sua propriedade e, por conseguinte, seu desencobrimento.

\begin{abstract}
A técnica não é perigosa. Não há uma demonia da técnica. O que há é o mistério de sua essência. Sendo um envio de desencobrimento, a essência da técnica é o perigo. Talvez a alteração de significado do termo "com-posição" torne-se agora mais familiar, quando pensado no sentido de destino e perigo. A ameaça, que pesa sobre o homem não vem, em primeiro lugar, das máquinas e equipamentos técnicos, cujo ação pode ser eventualmente mortífera. A ameaça, propriamente dita, já atingiu a essência do homem. O predomínio da com-posição arrasta consigo a possibilidade ameaçadora de se poder vetar ao homem voltar-ser para um desencobrimento mais originário e fazer assim a experiência de uma verdade mais inaugural (HEIDEGGER, 2008, p. 30-31).
\end{abstract}

Deste modo, a técnica moderna não se reduz a um mero produzir humano. Por isso é necessário encarar em sua propriedade o desafio que põe o homem a dispor do mundo como disponibilidade. Nesse sentido, Heidegger prossegue dizendo que onde domina sua composição, reina, portanto, um extremo perigo. E prossegue citando um poema de Hölderlin: “Ora, onde mora o perigo, é lá que também cresce o que se salva” (HEIDEGGER, 2008, p. $31)$.

Pensemos esta palavra de Hölderlin como o cuidado: o que significa "salvar?" Geralmente, achamos que significa apenas tempo, da destruição o que acha ameaçado em continuar a ser o que vinha sendo. Ora "salvar" diz muito mais. "Salvar" diz: chegar à essência, a fim de fazê-la aparecer em seu próprio brilho. Se a essência da técnica, a com-posição, constitui o perigo extremo e se também é verdadeira a palavra de Hölderlin, então o domínio da com-posição não se poderá exaurir simplesmente porque ela de-põe a fulguração de todo descobrimento, não poderá deturpar todo brilho da verdade. Ao invés, a essência da técnica há de guardar a si a medrança do que salva. Neste caso, uma percepção profunda o bastante do que é a com-posição, enquanto destino do desencobrimento não poderia fazer brilhar o poder salvador em sua emergência? (HEIDEGGER, 2008, p. 31).

Para o filósofo de Freiburg, até agora a palavra essência foi pensada relacionada ao senso comum e ao linguajar convencional. A vigência da técnica ameaça o desencobrimento e nenhuma ação da espécie humana poderá fazer frente a esse perigo. Já na

\begin{tabular}{|l|l|l|l|l|}
\hline Q Ponista Dialectus & Ano 9 & n. 17 & Maio - Agosto 2020 & p.152-165 \\
\hline
\end{tabular}


Grécia, segundo Heidegger, as artes ascenderam às alturas mais elevadas do descobrimento concedido pela técnica moderna.

Deste modo, o poético já possuía sua importância nas artes e, por não ser técnica, a essência da técnica precisa de uma consideração essencial de sentido, especialmente onde existe um espaço que seja estranho e ao mesmo tempo comum à técnica. A arte e a poesia proporcionam esse espaço comum. Para Heidegger, quanto mais pensarmos a questão da essência da técnica, mais misteriosa se torna para nós a essência da arte, pensada em sua condição de produção. Para o autor, o poético desempenha um papel de fundamental importância na existência humana. A arte poética não tem a intenção de direcionar padrões, mas possui o papel de desvelar aquilo que não aparece, diferenciando-se profundamente do pensar técnico moderno.

Na técnica moderna, o homem possui um pretenso domínio sobre os entes e sua linguagem mostra a estrutura desse domínio técnico. Porém, na poesia, a linguagem tem precedência sobre o homem; e as palavras se desvelam sem a necessidade de se enquadrarem a fundamentações e categorias técnico-científicas. Para Heidegger, é esse o caminho de pensamento que devemos cultivar, ou seja, responder ao apelo da linguagem, possibilitando reencontrar novamente seu modo de pensar originário e autêntico.

\section{A essência da técnica e a educação filosófica básica.}

O avanço da técnica atinge todos os âmbitos da vida humana, especialmente no desenvolvimento da ciência. Deste modo, a vida humana encontra-se fundamentalmente permeada pela técnica, enquadrada em uma estrutura que responde ao domínio da técnica. Por isso, a vida humana contemporânea responde aos anseios de uma vida marcada pelo domínio da natureza pelo homem. Assim, a exploração e a extração desenfreada dos recursos naturais como resposta às necessidades das comunidades humanas passam a ser regida e compreendida aos moldes de pensamento técnico. Neste sentido, o ambiente escolar também se encontra marcado pela técnica e seus desdobramentos, mesmo que a própria escola sempre seja um lugar de repensar e rediscutir a própria vida humana.

Assim, também a educação precisa ser repensada à luz da questão da técnica. A onipresença de dispositivos técnicos, comuns e quase invisíveis, tornam cada vez mais dominante a estrutura da técnica na vida. Os instrumentos tecnológicos estão cada vez mais

\begin{tabular}{|c|c|c|c|c|}
\hline Q Rovista Dialectus & Ano 9 & n. 17 & Maio - Agosto 2020 & p.152-165 \\
\hline
\end{tabular}


comuns nas relações sociais, nossa interação e aprendizagem passaram a ser controladas e mediadas por aparelhos celulares e computadores, sendo estes justificados pela promessa de uma didática mais prática e organizada.

Esses novos métodos e instrumentos tecnológicos estão cada vez mais presentes no campo pedagógico, especialmente na educação básica. Notamos a difusão do discurso que as novas tecnologias da informação são instrumentos que devem ser utilizados para a melhoria do ensino na educação básica, com a justificativa que essas tecnologias são capazes de trazer dinâmicas novas e mais atrativas para os alunos em sala de aula. Ou seja, vincula-se a ideia que o contato com as novas tecnologias é favorável ao contato dos estudantes ao acesso ao mercado de trabalho contemporâneo marcado pelo domínio de novos instrumentos tecnológicos.

A tecnologia então, é vista como um novo meio pelo qual serão solucionados uma série de problemas da prática de ensino. Aliado à capacitação profissional docente, o domínio da técnica multiplica e incentiva o uso de instrumentos tecnológicos sem antes haver uma adequada reflexão sobre o sentido de sua utilização.

Desde 'Ser e Tempo', Heidegger compreende o agir e a produção humanos são elementos constitutivos da vida fáctica. Contudo, à medida que a técnica é assumida como um aspecto essencial e absoluto da vida humana, o caráter fáctico parece ser encoberto. Apesar de Heidegger afirmar que a constatação antropológica e instrumental da técnica é correta, só nos leva a uma atitude livre a partir do questionamento da sua essência. Por isso, Heidegger sugere que a questão da técnica seja pensando de forma que nos conduza a caminho de questionamento da sua essência, desprendendo-se das interpretações vigentes. "Ele [Heidegger] nos atenta para o fato de que o próprio ser humano é jogado para desse projeto técnico maquiador de controle e domínio das coisas estando, assim como as coisas, disponível para ser encomendado e usado com máxima eficiência. (COCCO, 2006, p. 34).

Na medida em que notamos a espécie humana como seres da técnica, o modo-deser do Dasein é esquecido com mais esse recurso e dispositivo à mercê da técnica. O pensar está aliado ao desvelamento fora das estruturas da técnica moderna. "Deve haver, assim, a possibilidade de irmos para trás da ordem da natureza, para o intimo das mercadorias, das ferramentas, dos artefatos, para vermos aí um mundo encoberto” (STEIN, 2011, p. 195). Para Heidegger, o homem está no momento mais drástico do esquecimento do ser, a modernidade

\begin{tabular}{|c|c|c|c|c|}
\hline Govita Dialectus & Ano 9 & n. 17 & Maio - Agosto 2020 & p.152-165 \\
\hline
\end{tabular}


potencializa o perigo metafísico, transmutado em técnica. É o momento no qual o Dasein é transformado e compreendido em seu modo de ser técnico.

\begin{abstract}
Tudo ocupa agora um lugar bem definido que coincide totalmente com a função instrumental que a coisa reveste em tal sistema. As coisas são conhecidas a partir de sua funcionalidade, na sua instrumentalidade. A metafisica cumprida é. No seu sentido mais pleno e amplo, a técnica e instrumentalização geral do mundo. O ser do ente é reduzido à ocupação técnica. Do ser não fica mais nada, só restam os entes. (COCCO, 2006, p. 39).
\end{abstract}

Assim, Heidegger nos alerta acerca do perigo de perdermos novas possibilidades de ser-no-mundo. A técnica não se resume apenas a algo prático, é também uma compreensão de mundo onde as relações pessoais e com os dispositivos técnicos se manifestam segundo essa problemática.

O homem encontra-se cada vez mais apropriado pela técnica e seus desdobramentos. O pensamento técnico constitui de modo fundamental todo o processo social, constituindo o modo como vivemos e lidamos com as coisas. Contudo, o controle gerado pelos instrumentos tecnológicos, onde são depositados conhecimentos e informações de toda ordem, tornando o próprio homem conforme a técnica. Deste modo, como toda visão de mundo se insere na perspectiva técnica, a espécie humana passou a acreditar nela como a única forma de ser no mundo.

Assim sendo, pensar o ensino de filosofia na educação básica, tendo em vista a esfera da técnica, é uma tarefa importante para o professor de filosofia, especialmente na preocupação com a experiência de pensamento na escola, ainda que dominada pela técnica. Deste modo, educar filosoficamente também coloca em questão o modo como lidamos com as configurações atuais da vida com os outros. E esse questionamento passa pelo modo como lidamos com o mundo, via objetos tecnológicos, especialmente nas relações com os outros e com a natureza.

\footnotetext{
Por conseguinte, busca-se, apontar a necessidade da constituição de uma ontológica critica do objeto tecnológico, pois o mesmo uso de objetos tecnológicos, sem tal reflexão e definição, pode levar a constituição de uma ignorância profunda: a não percepção do que seja aquilo com qual lidamos e que nos constituí á medida que somos formados, seja na escola ou nos planos de nossa vida (WEBER, 2014, p. 93).
}

Por isso ressaltamos a necessidade de o professor de filosofia questionar o sentido de determinadas tecnologias e, por conseguinte, o seu sentido na formação dos estudantes.

\begin{tabular}{|l|l|l|l|l|}
\hline Qevista Dialectus & Ano 9 & n. 17 & Maio - Agosto 2020 & p.152-165 \\
\hline
\end{tabular}


Isto é, questionar até que ponto a técnica nos possibilita uma experiência de pensamento via dispositivos tecnológicos e suas possibilidades de acesso aos outros e ao mundo.

\begin{abstract}
Também na educação, o influxo da tecnologia tornou-se preponderante. A proliferação de matérias, livros, artigos, insistem em afirmar, e existem razões mais do que plausíveis para tal insistência, que uma dimensão decisiva do significado da educação no século XXI apenas configurada adequadamente quando forem incorporados os desafios lançados pela tecnologia (WEBER, 2014, p. 92).
\end{abstract}

Em Heidegger, a técnica é um perigo e ao mesmo tempo pode ser salvação para a humanidade e sua história. Para além de seu sentido mecânico e instrumental, a essência da técnica repousa sobre os problemas e soluções, especialmente para a compressão do domínio técnico no qual a humanidade está. Para Heidegger, tanto o progresso quanto a guerra são traços do seu domínio, pois transforma a vida humana em um interminável processo de objetificação. Heidegger afirma que a espécie humana compreendendo a técnica como algo simplesmente instrumental e passível de ser controlada. Contudo, está imersa em uma alienação essencial, pois é justamente nesse sentido que o homem passa a ser dominado: a técnica domina o homem e não o contrário. Está presente tanto em seus aparatos e máquinas quanto no fazer produtivo humano, respondendo aos modos de fazer e conhecer.

O mundo natural encontra-se marcado pelos instrumentos tecnológicos, inseridos na configuração técnica de mundo, como meros objetos a serem explorados, meios para um fim. Para Heidegger, a essência da técnica pode ser melhor entendida através da palavra alemã Gestell, enquanto possibilidade de desencobrimento. A essência da técnica, enquanto Gestell, produz uma visão de mundo onde todos os seres estão disponíveis como objetos, produtos a serem explorados.

A educação moderna, quando elege a utilidade e a rapidez como suas principais preocupações, demonstra como também está comprometida e dominada por essa problemática. Como diz Heidegger, "Quanto mais nos avizinharmos do perigo, com maior clareza começarão a brilhar os caminhos para que o salva, tanto mais questões haveremos de questionar. Pois questionar é a piedade do pensamento" (HEIDEGGER, 2008, p. 38).

É urgente a busca de um caminho que nos leve a repensar a essência da técnica, pois, ao compreendermos a técnica apenas como algo neutro que pode ser dominado de acordo com os interesses e fins do homem, caímos no seu velamento e ficamos sem enxergar sua relação com sua essência primordial. Trata-se de pensar um caminho que nos leve a pensar uma educação filosófica que não se rebaixe ao pensamento técnico vigente, uma

\begin{tabular}{|l|l|l|l|l|} 
Govista Dialectus & Ano 9 & n. 17 & Maio - Agosto 2020 & p.152-165 \\
\hline
\end{tabular}


educação filosófica que se concentre em formar indivíduos críticos e autênticos em sua forma de ser-no-mundo.

Ao analisarmos a questão da técnica em Heidegger e sua relação com o ensino de filosofia na educação básica, iniciamos uma provocação e um convite para pensarmos acerca da essência da técnica no mundo escolar, cada vez mais marcado pela técnica, desde métodos pedagógicos até a utilização de dispositivos sem a devida crítica. Neste sentido, é importante notar como a concepção instrumental e antropológica que caracteriza a técnica moderna também se encontra predominante no ambiente escolar, provocando uma prática educativa instrumental, pouco comprometida com os desafios do pensamento atual.

Os novos instrumentos tecnológicos foram capazes de modificar radicalmente o mundo, trouxeram facilidades e entretenimento cotidianos. A questão da técnica vai muito além dessas concepções ultrapassadas, carregando consigo o poder de transformar e destruir a própria humanidade. Comumente se pensa que a ciência preparou o caminho para o nascimento da técnica moderna. Contudo, notamos que foi justamente o contrário: da mesma forma que homem não pode dominar a natureza por completo, a não ser tecnicamente, trata-se do domínio da própria técnica e não do homem.

Portanto, os professores de filosofia têm uma oportunidade de repensar o próprio processo educativo, para além da utilização dos instrumentos tecnológicos. Os problemas pedagógicos da filosofia não são estranhos ao domínio técnico. Heidegger nos convida a refletir sobre a necessidade de termos um olhar mais crítico sobre esses instrumentos técnicopedagógicos ao invés de supervalorizarmos apenas o caráter instrumental da técnica moderna. Assim, o professor de filosofia possui o papel chave de questionar a própria escola, em sua transformação técnica, para construir um caminho de pensamento mais crítico.

É importante ressaltar que Heidegger não vê só o lado negativo da técnica, tampouco renega os benefícios que trouxe para humanidade. A questão é perguntar sobre sua essência como uma forma de repensar a própria vida humana.

Mesmo com as facilidades técnicas, a educação filosófica só pode se desvelar pelo diálogo. A linguagem é mais do que um instrumento de comunicação, ela nos constitui enquanto seres humanos inseridos no mundo em nosso modo de ser. O perigo presente no domínio da técnica não é apenas a destruição do homem e dos recursos naturais, mas também o perigo do fim do próprio pensamento originário. Por isso, a sala de aula aparece como um dos lugares de questionamento da técnica e sua presença na educação básica.

\begin{tabular}{|l|l|l|l|l|}
\hline Q Ronita Dialectus & Ano 9 & n. 17 & Maio - Agosto 2020 & p.152-165 \\
\hline
\end{tabular}




\section{Referências}

CERLETTI, Alejandro. O ensino de filosofia como problema filosófico. Belo Horizonte: Autêntica, 2009.

CHIZZOTTI, A. Pesquisa em Ciências Humanas e Sociais. São Paulo: Cortez, 1991.

COCCO, Ricardo. A questão da técnica em Martin Heidegger. In Controvérsia - v.2, n.1, janjun 2006, p. 34-54. São Leopoldo: Controvérsia, 2006.

DERRIDA, Jacques. Margens da Filosofia. Campinas: Papirus, 1991.

GADAMER, Hans-Georg "Hermenêutica em Retrospectiva: Heidegger em Retrospectiva", Vol. I. Rio de Janeiro: Editora Vozes, 2007.

GADAMER, Hans-Georg. Mis años de aprendizaje. Barcelona: Herder, 1996.

HEIDEGGER, M. Ensaios e conferências. Petrópolis/Bragança Paulista: Vozes/Editora Universitária São Francisco, 2008.

Introdução à metafísica. Rio de Janeiro: Tempo Brasileiro, 1969.

. Ser e Tempo. 3 $3^{\text {a }}$ Ed. Tradução Maria Sá Cavalcante. Rio de Janeiro: 2002.

. O fim da filosofia e a tarefa do pensamento. São Paulo: Abril Cultural, 1987.

Conferências e escritos filosóficos. São Paulo: Abril Cultural, 1973.

Que é uma coisa? Tradução de Carlos Morujão. Lisboa: 70, 1987.

KAHLMEYER-MERTENS, R. S. Heidegger e a Educação. Belo Horizonte: Autêntica, 2008.

RICOEUR, P. O Conflito das Interpretações. Porto: Rés-Editora, 2005.

SAFRANSKI, R. Heidegger, um mestre da Alemanha entre o bem e o mal, Trad. Lya Luft, São Paulo. Geração Editoral, 2000.

STEIN, E. Compreensão e Finitude, Ijuí: Editora UNIJUÍ, 2001.

Pensar e errar: um ajuste com Heidegger. Ijuí, Editora UNIJUÍ, 2011.

WEBER, J.F.A relação entre a meditação heideggeriana sobre a essência da técnica e o tema do Cuidado (Sorge). IXTLI - Revista Latinoamericana de Filosofía de la Educación. Volúmen 1, Número 1, 2014, p. 89-106.

\begin{tabular}{|l|l|l|l|l|}
\hline Qevista Dialectus & Ano 9 & n. 17 & Maio - Agosto 2020 & p.152-165 \\
\hline
\end{tabular}

